Caring for women wanting a vaginal birth after previous caesarean section: A qualitative study of the experiences of midwives and obstetricians.

Foureur M, Turkmani S, Clack DC, Davis DL, Mollart L, et al., Women and Birth, 2016

\title{
Caring for women wanting a vaginal birth after previous caesarean section: A qualitative study of the experiences of midwives and obstetricians
}

\section{ABSTRACT}

Problem: One of the greatest contributors to the overall caesarean section rate is elective repeat caesarean section.

Background: Decisions around mode of birth are often complex for women and influenced by the views of the doctors and midwives who care for and counsel women. Women may be more likely to choose a repeat elective caesarean section (CS) if their health care providers lack skills and confidence in supporting vaginal birth after caesarean section (VBAC).

Aim: To explore the views and experiences of providers in caring for women considering VBAC, in particular the decision-making processes and the communication of risk and safety to women.

Methods: A descriptive interpretive method was utilised. Four focus groups with doctors and midwives were conducted.

Findings: The central themes were; 'developing trust', 'navigating the system' and 'optimising support'. The impact of past professional experiences; the critical importance of continuity of carer and positive relationships; the ability to weigh up risks versus benefits; and the language used were all important elements. The role of policy and guidelines on providing standardised care for women who had a previous CS was also highlighted.

Conclusion: Midwives and doctors in this study were positively oriented towards assisting and supporting women to attempt a VBAC. Care providers considered that women who have experienced a prior CS need access to midwifery continuity of care with a focus on support, information-sharing and effective communication.

\section{Keywords}

Caesarean Section, Repeat; Caesarean Section; Vaginal Birth after Caesarean; Midwifery; Obstetrics 


\section{INTRODUCTION}

\section{Summary of Relevance}

\begin{tabular}{|l|l|}
\hline Problem & $\begin{array}{l}\text { In many countries, the caesarean section (CS) rate is rising and shows } \\
\text { little sign of reduction. One of the greatest contributors to the overall } \\
\text { caesarean section rate is elective repeat caesarean section. }\end{array}$ \\
\hline What is already known & $\begin{array}{l}\text { Decisions around mode of birth are complex for women and } \\
\text { influenced by the views and experiences of their doctors and } \\
\text { midwives. Women may be more likely to choose a repeat elective } \\
\text { caesarean section (CS) if their health care providers lack skills and } \\
\text { confidence in supporting vaginal birth after caesarean section (VBAC). }\end{array}$ \\
\hline What this paper adds & $\begin{array}{l}\text { Midwives and doctors in this setting were generally positive towards } \\
\text { supporting women to have access to VBAC. A number of elements } \\
\text { were seen as important to increase likelihood of success including } \\
\text { access to midwifery continuity of care with a focus on support, } \\
\text { information-sharing and effective communication. }\end{array}$ \\
\hline
\end{tabular}

\section{Background}

Caesarean section (CS) operation is a lifesaving intervention in the presence of an obstetric emergency. ${ }^{1,2}$ However, it is also associated with short and long term health risks for mother and baby and increases the economic burden on the health system. ${ }^{2-5}$ As the risks of performing CS may be greater than its benefits, ${ }^{6}$ it is only recommended for recognised clinical reasons. ${ }^{5}$ In 1985 , the World Health Organization (WHO) has suggested there are no additional advantages of CS above a rate of $10-15 \%{ }^{7,8}$ While many countries have safely achieved this, others, including Australia show a rise in the rate of CS far above this figure. ${ }^{1,2,5} 9,10$ One of the greatest contributors to the overall percentage of women having a CS is an elective repeat $\mathrm{CS}^{11,12}$

As an alternative to elective repeat CS, women who have had an uncomplicated pregnancy can be offered a vaginal birth after a caesarean section (VBAC). ${ }^{13}$ Many clinicians however are concerned about VBAC due to concerns about an increased risk of uterine rupture although these risks are low in absolute terms. ${ }^{14}$ This has resulted in the rate of VBAC declining in many high and middle income countries $^{9,15-17}$ despite studies demonstrating no significant difference in the risk of uterine rupture between women experiencing VBAC and women without a prior $\mathrm{CS}^{14,18-19}$

Decisions around mode of birth are complex and include an interplay between women's choices and health provider views, support from the health system, influences from the media and medico-legal concerns. ${ }^{3,4,20-24}$ Previous research has shown that a lack of providers' skills and confidence as well as fear of liability and legal action were the main factors that influence whether a woman is offered a vaginal birth or a repeat $\mathrm{CS}^{3,4,25,26}$ Given that most women rely on their provider's recommendations 
regarding the mode of birth, ${ }^{27}$ the provider's role in the process of decision making is likely to be a crucial influence. Equally, hospital guidelines play a role in determining the support of the local health services towards VBAC. Unfortunately, an analysis of guidelines has shown considerable inconsistency, making access to VBAC very limited in some hospitals. ${ }^{20,28}$

The way information is communicated to women is known to influence women's decision-making around childbirth. ${ }^{26,27,29}$ Information provided by the media, family and friends has a significant influence on women's choice towards CS. For example, one Swedish study showed that it was difficult to change women's minds towards natural birth once they had decided to have an elective $\mathrm{CS}^{23}$ Therefore, the way clinicians communicate with women after the primary CS is also likely to be an important mediator in the decisions around the next birth.

Most studies in the area of VBAC are focused on clinical outcomes or perspectives from women; few have examined the experiences of the providers, which are likely to drive behaviour.21,24 Therefore the aim of this study was to explore the views and experiences of providers in caring for women who would be eligible for a VBAC. In particular, we were interested in the maternity care providers' communication of risk to women, the influence of their experience on their practice, and their views about what hinders or helps women to achieve a VBAC.

\section{METHOD}

A descriptive interpretive method ${ }^{30,31}$ was utilised to understand the experiences of health care providers in relation to the care of women who had a CS in a previous pregnancy. Focus group discussions were used as the primary approach to data collection. Ethical approval was gained from relevant health service and university Human Research Ethics Committees (1207-215M).

The study was conducted in a maternity unit in an outer metropolitan area of New South Wales (NSW), Australia. The hospital offers women access to VBAC and is fully staffed and equipped for care and monitoring in labour, emergency CS and neonatal resuscitation. It caters for over 2600 births annually, 32,33 and has an overall CS rate of $30 \%$. The hospital is typical of many maternity units across the country. ${ }^{33}$

This maternity unit has a midwife whose employed role is to meet with all women who have experienced a prior CS in order to ensure all VBAC and/or elective CS options are explained so that women know what choices are available. Her role is well recognised with her attendance and reporting of VBAC rates regularly required at multidisciplinary unit meetings. 
The study recruited a purposive sample of two professional groups involved in women's care at the hospital, specifically midwives and obstetricians. Information flyers were displayed in the staff common areas and an invitation letter was sent by internal mail to all obstetric medical staff and midwives providing antenatal and intrapartum care to women who had experienced a previous CS. This included midwives working in the medically-led antenatal clinic, the midwife-led antenatal clinic, the midwifery continuity of care and the birth unit.

Focus group discussions (FGD) were simulated initially through the use of the trigger question: 'can you tell us about your experience of caring for women who have had a previous CS?' The facilitators asked further probing questions to deepen the group's reflection and recall about the issue. Each person had an opportunity to speak, add to the conversation and build on or contradict one another's ideas.

Four FGDs with a total of 18 participants were conducted between March and September 2014 by one or two members of the research team (MF, ST). The facilitators were experienced research and clinical midwives who knew some of the participants professionally. One focus group comprised of three obstetricians and one midwife (FGD 1) and the others comprised of groups of five, six and three midwives (FGD2, FGD3 and FGD4 respectively). The FGDs were scheduled the time of clinical handover to avoid any disruption in the provision of women's care.

Following consent, the FGDs were audio-recorded and transcribed. Data were analysed systematically using thematic analysis employed in five stages known as fundamental or generic qualitative description. ${ }^{34,35}$ Each transcript was read several times by five individual research team members (MF, LM, BL, ST, DC) to familiarise with the content. The initial thematic analysis was conducted by manual coding based on the objectives of the study; identifying codes and grouping them into preliminary themes. Then, themes were grouped together to facilitate interpretation and data were summarised in charts with representative quotes to illustrate themes. To ensure consistency of the analysis, these themes and sub-themes were discussed and consensus among researchers was reached. ${ }^{36,37}$

\section{FINDINGS}

Three central themes emerged from the analysis; 'developing trust', 'navigating the system', and 'optimising support'. Under each main theme, subthemes were identified. These are presented in the following section with illustrative quotations. 


\section{Developing Trust}

The first main theme was the importance of developing trust between women and providers. Five sub themes were identified: the impact of past professional experiences; continuity and relationships; weighing up risks versus benefits; work as a team; and communication and language.

The impact of past professional experiences mediated the experiences of the participants, their understanding of the guidelines around their care and the way in which they explained risks and benefits to women. For example, one midwife said:

...I feel confident looking after a VBAC lady...Although my main concern at the back of my mind is the monitoring ... 'because she'll need that extra monitoring ... so in the back of my mind I always try and think that active labour and being upright and [leaning] forward for a VBAC is more... Is really important... we'll always get a telemetry monitor so they can be mobile, active and they have more of a chance of a vaginal birth by doing that. (Midwife FGD4)

The potential adverse implications of a VBAC were also expressed by the doctors, especially if their past experiences included an adverse outcome following a VBAC. This was an anxiety for the doctors and played on their minds when they were attending women in labour. These two quotes highlight these concerns:

But some of the times when you go into caesars, and you see how paper thin that lower segment is, it's terrifying. You just think, you know, if you have contractions on that, your chances of beating it, it just goes. Like, you don't know. (Doctor FGD1)

I'd hope for a VBACI think. But I get a lot more nervous ... Knowing what I know. (Doctor, FGD1)

Continuity and the relationships that health care providers developed with women were an important element of quality care to support VBAC. This was expressed from both midwives and doctors and it contributed to developing and maintaining trust. As an illustration, participants said:

I think a lot [of] positive reinforcement is the way to go. And look, I think that continuity of care too. I know that the one-on-one midwifery care certainly helps a fair bit too. (Doctor,FG1)

I was seeing her antenatally. I think maybe she had one visit with somebody else. But I was lucky enough to have her in labour. And know what's important for her. And she had a lovely 
vaginal birth... So, that continuity of care... she felt she could trust me... She knew what I wanted out of it as well. (Midwife FGD3)

In Australia, access to midwifery continuity of care for VBAC is limited because women with risk factors (eg. a previous CS) are often excluded from midwifery-led models of care. Participants felt that this was problematic considering the benefits of continuity of care for women who had a previous CS. Two midwives explained this dilemma saying:

Unfortunately under midwifery group practice these women [women wanting a VBAC] don't fit that model but that would be really good because they've built up that relationship with that person that they know and the trust is with them. (Midwife FGD2)

I think that continuity of care makes a big difference, It's always bothered me that group practice midwives exclude those women from their program because it's a low risk model. (Midwife FGD4)

Developing trust meant being able to weigh up risks versus benefits with the women. Midwives and doctors spoke of the need to be able to provide information and then support women's decision making. Some midwives chose to focus on the chance of normal birth rather than the risks of a CS. For example:

It's this idea of risk and the chance of risk. It's like everyone's innocent until proven guilty. You have a good chance of having normal [birth] rather than chance of caesar with anybody who comes in, Primip or VBAC. You have the same chance of good outcomes... So it's no different from any other women. (Midwife FGD3)

Using language that weighed up risks and benefits but did not frighten women or dismiss the risks was important. A discussion about the risk of uterine rupture was particularly challenging, for example:

We talk to her about the scar and the uterus after the first one. The scar coming undone rather than-Or, you know... Uterine rupture is very scary, I think, you know. It gives the kind of images that frighten women. (Midwife FGD2)

There was also the challenge of not being too dismissive as highlighted here:

But people do come in and worry about it [uterine rupture]. I must admit I rarely give numbers. It's more like ..."rare as hen's teeth" ... phrases like that, that I can use so you would have to be incredibly unlucky. (Doctor FGD1) 
Participants also recognised that some health care providers were more negative than others and this influenced practice. For example:

There were a couple of Registrars [trainee obstetricians] that I thought were a bit negative. But I don't think they're here now. Because they seemed to really focus on the risks, I thought. And with the VMOs [Visiting Medical Officers/Consultant Obstetricians], I think are pretty good with it. (Midwife FGD2)

Developing trust also meant the health care providers needed to work as a team so that women received consistent information. Participants recognised that women will not trust them if the information they received was unnecessarily negative or did not follow the policies. For example:

... women know that they may not see the face that is familiar... but they will hear all the same information through every single visit... (Midwife FGD3)

I think we all need to be working under the same motivation as far as working together with the same sort of policies. I think education is huge so women need to be educated in a positive way. Not in a negative or fear factor. (Midwife FGD4)

The final sub-theme under Developing Trust was the importance of effective communication and language by the health care providers. This was especially evident for the word 'rupture' as indicated in these quotes:

I think if they use the word "rupture" themselves, I sometimes say, "Look, that's a very dramatic way..." You know, talking about what actually happens. You've got to explain to them that it's not actually a...uterus exploding. (Midwife FGD2)

I talk to them at the first visit. And Dr [xxx]'s actually just told me not to call it "uterine rupture", 'because that's a very negative term. He prefers "uterine scar dehiscence". (Doctor FGD1).

\section{Navigating the System}

The second main theme was navigating the system, which highlights how the health system affects women's choices. The two subthemes were system and control.

The system was not always seen as one that was supportive of VBAC, and it sometimes impacted on effective communication. For example, short appointments limited the time available to discuss the benefits and risks of VBAC and develop a trusting relationship. One midwife said: 
Of course time is a restriction for us. We have twenty-minute appointments and ... You don't have a lot of time for a lot of discussion. And they say that booking-in [visit],, we should probably try and cover it then... Information overload for the poor women... But, yeah. It's time. Time is a factor. But we have a "Towards Normal Birth" [specific program] midwife who is [very available] to us. (Midwife FGD2)

Participants reported that not all obstetricians followed the hospital policies that supported VBAC. Therefore women often went through pregnancy without obstetric support for VBAC. One midwife highlighted this by saying:

It depends on the doctor that they get and how it's put to them. Because sometimes they go in [to the antenatal visit with the doctor] going, "I'm not sure. I'm not sure". They come back with, "No, I want a caesarean. Because it's [a VBAC] not safe". (Midwife FGD3)

Navigating the system raised questions about control - for the women and for the health care providers. Participants in the study noted the need for women to make an informed decision, and for this decision to be supported. While many providers were ultimately supportive of VBAC, they wanted women to be able to take control with their own decisions. One midwife explained this as:

So when ...I ask women, I say, "Are you happy with your decision?" And when they say, "I am so relieved I have made my decision and I am happy" then I say, "Own it". "Keep it going... If your mind changes in any way, ask us questions. If you're "umming and arring" on anything, let us know. But own your decision." (Midwife FGD3)

While the rhetoric in this particular hospital was about supporting women's choice and enabling women to feel in control, this did not always occur. Miscommunication and fear-mongering impacted on women's decisions, for example:

They'd [the women] get to thirty-six weeks [pregnant] and then they'd see the Registrar and they would scare them. And then they would just say, "Oh well I'll have a caesarean". (Midwife FGD4)

Participants recognised that VBAC introduced a level of uncertainty for women and that not all were prepared for this. The data highlight the importance of control and certainty for women. Participants felt that while women wanted to be in control, this was not always possible in a labour and so opting for a CS may have re-introduced a measure of control. 
Some of them (women), they just quite like a planned thing. They have the caesarean. They have a date. They know a month before when it's going to be then... I hear that quite a lot.... that's a major thing that they like.... to do it. (Midwife FGD2)

...The other big impact is the partner who doesn't want to watch her go through all those hours of pain again. And they have a caesarean at the end of it. (Midwife FGD3)

\section{Optimising Support for VBAC}

The third main theme, Optimising Support for VBAC, defined and reflected the role of policy and guidelines on providing standardised care for women who had previous CS and are interested in VBAC. Participants were keen to provide women with information so that they were able to support and respect their decision about their mode of birth. Having a dedicated midwife, known as the "Towards Normal Birth" midwife, was seen as an important element of the service for women. One midwife said:

And I've noticed that even in the last couple of years since we've had that "Towards Normal Birth" midwife, what I would see happening is that women would want a VBAC, they would come through the clinic, get to their thirty-sixth week visit with the doctor and... Change their mind. Now, I find that with our "Towards Normal Birth" midwife, she's also there and she's informing the women [about their VBAC options], I find that that's not happening as much. (Midwife FGD4)

One of the doctors also said:

I'd have to say that I remain impartial to it to provide the woman with all the information. And don't strongly force them in either direction. But talk about the positives of a vaginal birth but also the risks of a VBAC even though they're small, and let them make their own minds up. A lot of them come in with a pre-conceived idea. And I don't push them really far from that apart from giving them the facts. (Doctor FGD1)

Respecting women's decision was respected by participants, even if they did not choose a vaginal birth:

If somebody came in saying, "I want a caesar". Or "I don't want..." I don't give them a recommendation-But I say, "You need to make the decision based on the facts that I'm giving you". I don't push them either way. (Doctor FGD1) 
Once women had made a decision to have a vaginal birth, participants felt that promoting an active labour was important. One doctor explained:

So, I generally try and encourage them to be as mobile as possible. I just find that helps with [progress in labour] but they've got to think about... I want to get their pain relief options so... I don't want them feeling that they can't have an epidural, for example, just because they've got a scar in the uterus. So... Yeah, but they've got to have continuous CTG monitoring and as long as we've got the wireless ones [telemetry monitor] then she's right to be able to get up and walk 'round, in and out of showers and massages and things like that, so... But I know that the one-on-one midwifery care certainly helps a fair bit too. (Doctor FGD1)

\section{DISCUSSION}

Overall, participants in this study represented themselves to be positively oriented towards assisting and supporting women to attempt a VBAC. A major theme of optimising support saw both midwives and doctors assert the potential benefits of a continuity of care to enable the formation of a trusting relationship. They saw midwifery care as being integral to the decision to attempt and ultimately achieve a VBAC. This finding is supported by other studies that show types of provider have an effect on the outcome of care for women ${ }^{14,19,38}$ with midwifery led care associated with higher rates of VBAC $^{15,20,39}$ compared with obstetric led care..$^{14,19,40}$

Provider attitudes during care ${ }^{21}$ have been shown to have an impact on the woman's desired mode of birth. ${ }^{21,41}$ This study has shown that the providers generally had positive experiences about supporting VBAC however pressures sometimes meant there was insufficient time to discuss issues with women. A busy workload has been seen as a significant barrier to providing adequate decisionmaking support to women in other studies. ${ }^{23}$ Other barriers include VBAC discussions being seen as beyond the scope of midwifery practice, despite the evidence associating decreased midwifery care with decreased VBAC. ${ }^{4,14}$ The leadership role of midwives in the management of labour and birth positively influences the confidence of women to choose a $\mathrm{VBAC}^{42}$ further highlighting the importance of the views of midwives in our study.

Past professional experiences meant that doctors and midwives had slightly different perspectives on the issue of trusting the woman's body. Foremost in the mind of the doctors, who had sometimes seen the "paper-thin" lower segment at CS, was concern that the uterine tissues appeared on the verge of separating. This often provoked anxiety during an attempted VBAC. The midwives did not 
express such fears concerning the risks of VBAC since their experiences had largely been positive ones where women succeeded in giving birth safely.

The midwives and doctors also recognised the shortcomings of the maternity system in which they worked. Even in this supportive environment, women could have their choices and options limited. It was reported that women often had little control over who they saw for care, or for how long they could spend at each visit, making fully informed decision making less unlikely. In this setting, the option of continuity of care was only available to those few women who fitted strict criteria and where spaces were available on a midwifery continuity of care model.

All participants acknowledged the power of words, and recognised the potential influence of their personal preferences about VBAC on women's decisions. Taking care to be impartial was emphasised particularly by the doctors in one focus group who used carefully chosen words to describe the risks of VBAC. Respect for a woman's decision, whether opting for an elective CS or VBAC, was paramount. For example one midwife described how she encouraged women to 'own your decision', whatever that may be. In this way the midwife was helping the woman to feel in control of her decision-making and set an orientation and expectation for whatever was to follow.

Provider centred interventions and models that facilitate shared decision-making with women are important in supporting women to attempt, and be successful at, VBAC. ${ }^{21,43,44,45}$ Providers have moral, ethical and professional obligations to support women in their choices and to provide appropriate information and care. ${ }^{45,46}$ One to one midwifery care during pregnancy, labour and birth is associated with an informed decision and lower rate of CS. ${ }^{22,23,26,47}$

The limitations of this study are that it is possible that participants filtered their responses to reflect what they imagined the interviewer or their fellow participants wanted to hear. This is common with any focus group discussion. The lead obstetrician of the unit in which the research took place was very pro-VBAC and went to great lengths to encourage a similar orientation in the medical and midwifery staff. Participants may have felt inhibited in expressing any other views. In maternity units without a medical and/or midwifery champion for supporting women to experience VBAC, the findings may differ. This study is therefore not generalisable but nevertheless provides important insights that may be applicable in other settings/contexts.

\section{CONCLUSION}

This study has highlighted the importance of continuity of care and carer for women who have experienced a prior CS. All the participants in this study noted that this was a key to developing trust, navigating the system and optimising care to assist women in making an informed decision about 
VBAC. The effective and consistent provision of information to women with a past history of CS may also improve communication between women and staff concerning the risks and benefits of VBAC and provide women with truly informed choice.

\section{Acknowledgements}

Thank you to the participants who gave up their time to attend the focus groups. We thank the members of the BUMP Steering Committee at Gosford Hospital for their leadership and ongoing support. Thank you also to Dr Amy Monk for editing advice on the final draft of manuscript.

\section{Role of the Funding Source}

The study was funded by a National Health and Medical Research Council (NHMRC) Project Grant (ID APP1023352) and administered by the University of Technology Sydney. The funding source had no role in: study design; the collection, analysis and interpretation of data; the writing of the report; and in the decision to submit the article for publication. 


\section{REFERENCES}

1. Stjernholm YV, Petersson K, Eneroth E. Changed indications for cesarean sections. Acta Obstetricia et Gynecologica Scandinavica 2010; 89(1): 49-53.

2. Betrán AP, Merialdi M, Lauer JA, et al. Rates of caesarean section: analysis of global, regional and national estimates. Paediatric and Perinatal Epidemiology 2007; 21(2): 98-113.

3. Churchill $\mathrm{H}$, Francome $\mathrm{C}$. British midwives' views on rising caesarean section rates. British Journal of Midwifery 2009; 17(12): 774-8.

4. Cox K. Providers' perspectives on the vaginal birth after cesarean guidelines in Florida, United States: a qualitative study. BMC Pregnancy and Childbirth 2011; 11(1): 72.

5. Souza JP, Gülmezoglu AM, Lumbiganon P, et al. Caesarean section without medical indications is associated with an increased risk of adverse short-term maternal outcomes: the 2004-2008 WHO Global Survey on Maternal and Perinatal Health. BMC Medicine 2010; 8: $71-$.

6. Niino Y. The increasing cesarean rate globally and what we can do about it. Bioscience Trends 2011; 5(4): 139-50.

7. World Health Organization. WHO Statement on Caesarean Section Rates. Geneva, Switzerland: World Health Organization 2014. p. 8.

8. World Health Organization. Appropriate Technology for Birth. The Lancet 1985; 326(8452): 436-7.

9. Austarlian Institute for Health and Welfate. Australia's Health 2012. Canberra: Australian Institute of Health and Welfare, 2012.

10. Commonwealth of Australia. Improving Maternity Services in Australia: Report of the Maternity Services Review. Canberra: Commonwealth of Australia; 2009.

11. Stavrou E, Ford J, Shand A, Morris J, Roberts C. Epidemiology and trends for Caesarean section births in New South Wales, Australia: a population-based study. BMC Pregnancy and Childbirth 2011; 11(1): 8.

12. McCourt C, Weaver J, Statham H, Beake S, Gamble J, Creedy DK. Elective Cesarean Section and Decision Making: A Critical Review of the Literature. Birth: Issues in Perinatal Care 2007; 34(1): 65-79.

13. Foureur M, Ryan C, Nichol M, Homer C. Inconsistent Evidence: analysis of six national guidelines for vaginal birth after caesarean section (VBAC). Birth 2010; 37 (1): 3-10. 
14. Avery MD, Carr CA, Burkhardt P. Vaginal Birth After Cesarean Section: A Pilot Study of Outcomes in Women Receiving Midwifery Care. Journal of Midwifery \& Women's Health 2004; 49(2): 113-7.

15. Homer CS, Besley K, Bell J, et al. Does continuity of care impact decision making in the next birth after a caesarean section (VBAC)? a randomised controlled trial. BMC Pregnancy Childbirth 2013; 13: 140.

16. Homer CSE, Johnston R, Foureur MJ. Birth after caesarean section: changes over a nine-year period in one Australian state. Midwifery 2011; 27(2): 165-9.

17. MacDorman M, Declercq E, Menacker F. Recent Trends and Patterns in Cesarean and Vaginal Birth After Cesarean (VBAC) Deliveries in the United States. Clinics in Perinatology 2011; 38(2): 179-92.

18. Alexander J. The MFMU units cesarean registry: Fetal injury associated with cesarean delivery. American Journal of Obstetrics and Gynecology 2004; 191(6, Supplement): S153.

19. Carr CA, Burkhardt P, Avery M. Vaginal birth after cesarean birth: A national survey of US midwifery practice. Journal of Midwifery \& Women's Health 2002; 47(5): 347-52.

20. Toohill J, Gamble J, Creedy DK. A critical review of vaginal birth rates after a primary Caesarean in Queensland hospitals. Australian Health Review 2013; 37(5): 642.

21. Halvorsen L, Nerum H, Sørlie T, Øian P. Does counsellor's attitude influence change in a request for a caesarean in women with fear of birth? Midwifery 2010; 26(1): 45-52.

22. Gunnervik C, Josefsson A, Sydsjö A, Sydsjö G. Attitudes towards mode of birth among Swedish midwives. Midwifery 2010; 26(1): 38-44.

23. Karlström A, Engström-Olofsson R, Nystedt A, Thomas J, Hildingsson I. Swedish caregivers' attitudes towards caesarean section on maternal request. Women and Birth 2009; 22(2): 5763.

24. Wells CE. Vaginal Birth After Cesarean Delivery: Views from the Private Practitioner. Seminars in Perinatology 2010; 34(5): 345-50.

25. Dahlen H. Undone by fear? Deluded by trust? Midwifery 2010; 26(2): 156-62.

26. Weaver J. Caesarean section and maternal choices. Fetal and Maternal Medicine Review 2004; 15(1): 1-25.

27. Kaimal AJ, Kuppermann M. Understanding risk, patient and provider preferences, and obstetrical decision making: approach to delivery after cesarean. Seminars in Perinatology 2010; 34(5): 331-6.

28. Lyerly AD, Little MO. Toward an Ethically Responsible Approach to Vaginal Birth After Cesarean. Seminars in Perinatology 2010; 34(5): 337-44. 
29. Kennedy HP, Grant J, Walton C, Sandall J. Elective caesarean delivery: A mixed method qualitative investigation. Midwifery 2013; 29(12): e138-e44.

30. Thorne S, Kirkham SR, MacDonald-Emes J. Interpretive description: A noncategorical qualitative alternative for developing nursing knowledge. Research in Nursing \& Health 1997; 20(2): 169-77.

31. Sandelowski M. Whatever happened to qualitative description? Research in Nursing \& Health 2000; 23(4): 334-40.

32. Central Coast Local Health District. Caring For The Coast; Celebrating 70 years. Caring For The Coast. 2015, Gosford.

33. NSW Department of Health. NSW Mothers and Babies 2013. In: Health NMO, editor. NSW, Australia: NSW Health; 2013.

34. Merriam SB. Qualitative Research : A Guide to Design and Implementation : A Guide to Design and Implementation (3rd Edition) Wiley; 2014.

35. Caelli K, Ray L, Mill J. 'Clear as Mud': Toward Greater Clarity in Generic Qualitative Research. International Journal of Qualitative Methods 2003; 2(2): 1.

36. Burnard P. A method of analysing interview transcripts in qualitative research. Nurse Education Today 1991; 11(6): 461-6.

37. Graneheim UH, Lundman B. Qualitative content analysis in nursing research: concepts, procedures and measures to achieve trustworthiness. Nurse Education Today 2004; 24(2): $105-12$.

38. Murphy PA, Fullerton JT. Measuring outcomes of midwifery care: Development of an instrument to assess optimality. Journal of Midwifery \& Women's Health 2001; 46(5): 27481.

39. Hall A, Hardwick T, Hauck Y. Women's satisfaction with the Next Birth After Caesarean service. Midwifery News 2012: Winter: 7-9.

40. Butler J, Abrams B, Parker J, Roberts JM, Laros Jr RK. Supportive nurse-midwife care is associated with a reduced incidence of cesarean section. American Journal of Obstetrics and Gynecology 1993; 168(5): 1407-13.

41. Catling-Paull C, Johnston R, Ryan C, Foureur MJ, Homer CSE. Non-clinical interventions that increase the uptake and success of vaginal birth after caesarean section: a systematic review. Journal of Advanced Nursing 2011; 67(8): 1662-76.

42. Hangsleben KL, Taylor MA, Lynn NM. VBAC program in a nurse-midwifery service. Five years of experience. Journal of Nurse-Midwifery 1989; 34(4): 179-84. 
43. Lundgren I, Smith V, Nilsson C, et al. Clinician-centred interventions to increase vaginal birth after caesarean section (VBAC): a systematic review. BMC Pregnancy and Childbirth 2015; 15(1): 16.

44. Paterson-Brown S, Amu O, Rajendran S, Bolaji II. Should doctors perform an elective caesarean section on request?Yes, as long as the woman is fully informed: Maternal choice alone should not determine method of delivery. BMJ 1998: 317:462.

45. Bewley S, Cockburn J. I. The unethics of 'request' caesarean section. BJOG 2002; 109(6): 5936.

46. McFarlin BL. Elective cesarean birth: Issues and ethics of an informed decision. Journal of Midwifery \& Women's Health 2004; 49(5): 421-9.

47. Laufer A, Hodenius V, Friedman L, et al. Vaginal birth after cesarean section. Nursemidwifery management. Journal of Nurse-Midwifery 1987; 32(1): 41-7. 